\title{
Increase of energy efficiency of electric power distribution networks by adjustment of reactive energy consumption in a traction network
}

\author{
Natalia Shurova ${ }^{1, *}$, Valerii $\mathrm{Li}^{1}$ \\ ${ }^{1}$ Far Eastern State Transport University, Serysheva st. 47, Khabarovsk, Russia
}

\begin{abstract}
In the past few years, there has been a trend towards an increase in the volume of transportation by railway. At the same time, the load on the railway infrastructure increases, in particular, on the traction power supply system. It is necessary to solve the problem of increasing the energy efficiency of the external electric power supply system in the conditions of growing freight turnover and taking into account the uncertainty of the initial data. The paper considers one of the methods of strengthening the traction power supply system. Based on the results of the study, an algorithm was developed for selecting the installation sites and power of compensating devices in a traction network in the conditions of increasing freight turnover and under the condition of increasing the energy efficiency of the external power supply system of traction substations due to unloading of supply lines by reactive power and leveling the load in phases. This methodology includes predicting power consumption, determining the installation sites and power of compensating devices in the traction network under condition of uncertainty of the initial data, and then assessing the energy efficiency of the decision made. A calculation was carried out for the proposed algorithm for a section of the Far Eastern Railway which includes nine traction substations.
\end{abstract}

\section{Introduction}

The railway of an alternating current is a specific consumer of electric energy. Characteristic features are sharply variable nature of the load, uneven loading of power transmission lines in phases, and a large proportion of the consumed reactive energy. All of the above features have a negative impact on the operating mode of the power system.

Even now, railway transport consumes more than $4 \%$ of all generated electric energy in the country. And this figure will grow, tacking into account the planned by "Strategy for the development of railway transport in the Russian Federation until 2030" and "Strategy for the development of the "RZD" holding for the period until 2030" growth in the volume of freight and passenger traffic.

Moreover, with the growth of traffic volumes, consumption of both active and reactive energy is increasing. Figure 1 shows the dynamics of changes in electric power consumption

\footnotetext{
*Corresponding author: lunor92@mail.ru
} 
and freight turnover from 2008 to 2017 on the section of the Far Eastern Railway. In the indicated period, the growth of freight turnover was $83.5 \%$.

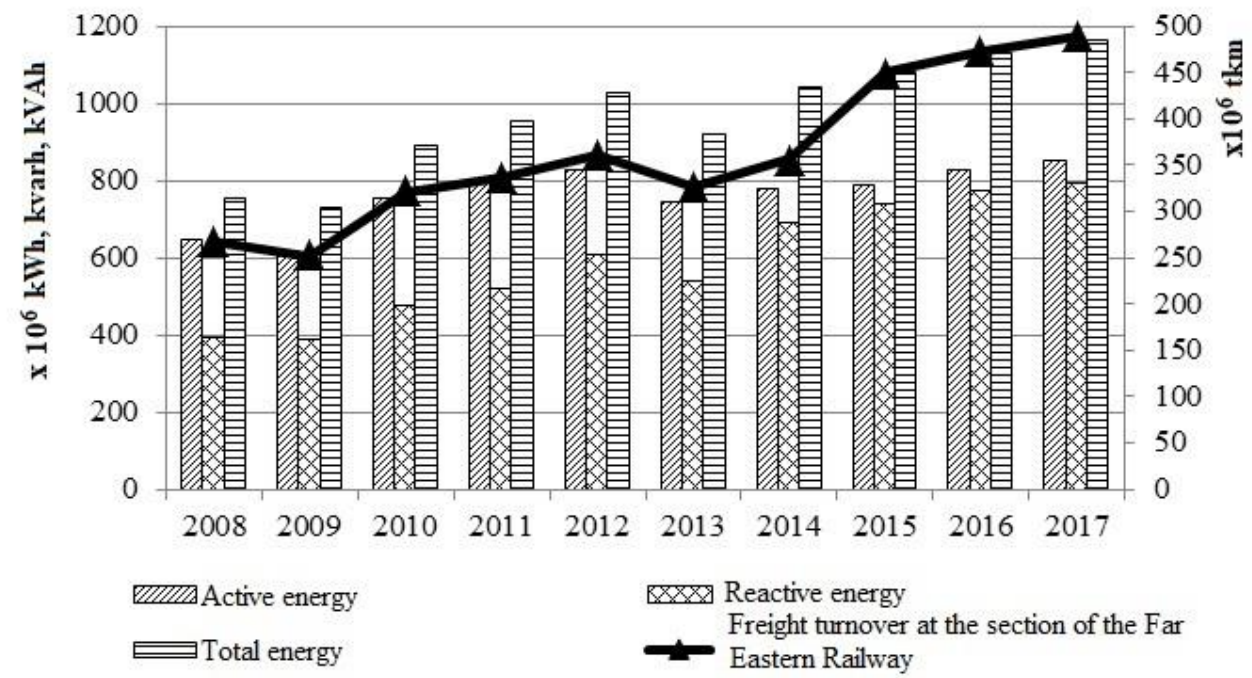

Fig. 1. Dynamics of changes in freight turnover and consumed electric energy at the section of the Far Eastern Railway.

The figure shows the relationship between power consumption and freight turnover. Starting from 2012, the percentage of reactive energy in the structure of total energy consumption has significantly increased. In 2008, active and reactive power factors were 0.85 and 0.61 , respectively, and in $2017-0.73$ and 0.93 . During the period under consideration, the reactive power factor increased by $53 \%$, and the active power factor decreased by $14 \%$. At the same time, the losses of electric power in the power transmission lines of the external power supply system increased by $137 \%$, and the voltage losses from distribution to traction substations increased by $53 \%$.

The installation of devices for compensation of reactive power in the traction network can solve this problem. The installation of these devices will reduce the flow of reactive energy in the system of external power supply of traction substations, and due to this, voltage and power losses in power transmission lines and transformers will decrease $[1,2]$. In addition, the correctly selected power of the compensating device will increase the available power of the traction substation and reduce the need to increase the power of power transformers. Besides, a rational distribution of the power of compensating devices between the phases of the traction power supply system makes it possible to increase the uniformity of the loading of phases of the external power supply system.

To date, there are several ways to determine the installation sites and power of compensating devices. The instruction approved by JSC "RZD" aims to maintain the voltage level in the contact network. The criteria for determining the power of the compensating device is the voltage level and the value of the capital costs [3]. In the calculations, two options are considered: the use of longitudinal and transverse compensation to increase the voltage level in the contact network. Based on the results of the calculations, a result is chosen which will allow a given voltage level to be achieved at lower capital costs.

In paper [1], the power of the compensating device is chosen based on the greatest economic effect with observance of the necessary technical characteristics. In the calculations, only networks of one voltage class $(27.5 \mathrm{kV})$ are considered, and the external power supply system is represented by a power source and reactive resistance. 
In papers $[4,5,6]$, the main emphasis is on choosing the installation site of the compensating device: traction substation, switching station, and the point of parallel connection. In paper [4], a minimum of active power losses was adopted as a criterion for choosing the power of the compensating device. Paper [5] describes the choice of power and installation sites of devices for transverse compensation of reactive power, depending on the power scheme and the sectionalization of the contact network, as well as on the traction power system of an alternating current. Criteria for reducing unsinusoidality and unbalance of voltage are used to determine the power of the compensating device in paper [6]. The authors propose to use filter compensating devices tuned to a frequency of $150 \mathrm{~Hz}$ to reduce the unsinusoidality of voltage. And to reduce unbalance, it is proposed to install capacitor batteries in the lagging and advanced phases of the traction substation.

Paper [7] is devoted to the choice of the power of static capacitors using flexible power transmission. The optimal installation site of the compensating device in the power system is determined by the analysis of the stability of the system under small disturbances with the determination of the number of possible installation sites and the comparison of these installation sites by analyzing the transient processes in the power system under various design cases. In this paper, the main criterion is the stable operation of a closed energy system.

In papers [1-6], when determining the power of compensating devices, the improvement in the parameters of the regime of the traction power supply system alone is taken into account, and the external power supply system is represented by an abstract energy source and an equivalent resistance. This paper is devoted to strengthening the traction power supply system taking into account the impact on the parameters of the traction power system.

\section{Materials and methods}

The paper proposes a methodology for selecting the installation sites and the power of compensating devices in the traction network, taking into account the growth in traffic volumes and the uncertainty of the initial data caused by this growth. The algorithm of the proposed methodology is presented in Figure 2. The proposed algorithm allows predicting the power consumption taking into account the changes in traffic volumes. The methodology of determining the power of the compensating device reveals the degree of influence on the external power supply system.

At the first stage of the algorithm, the initial data is collected and processed for forecast evaluations. The initial data is a statistical sample of the values of active and reactive energy consumed by each design substation, as well as the characteristics of the transportation process: freight turnover, the number of trains passing the section, average speed and mass of trains, average train length, traffic density per kilometer, and number of empty trains.

The second block of the algorithm is the prediction of power consumption. Depending on the required accuracy, one of the two prediction methods is chosen. The first is based on correlation and regression analysis [8-10]. This method showed a prediction error not exceeding $10 \%$ and is recommended for use in design practice and operation. Advantages of this method are the ability to determine the interval of predicted values of power consumption and no need for additional software. The second method is based on artificial neural networks. This method is more accurate (an error of up to $1 \%$ ) [11,12], but more expensive, since it requires additional expensive software. In particular, it is possible to use the software complex Matlab [12]. Therefore, this method of forecasting is recommended to be used only if it is necessary to improve the accuracy of the forecast. 


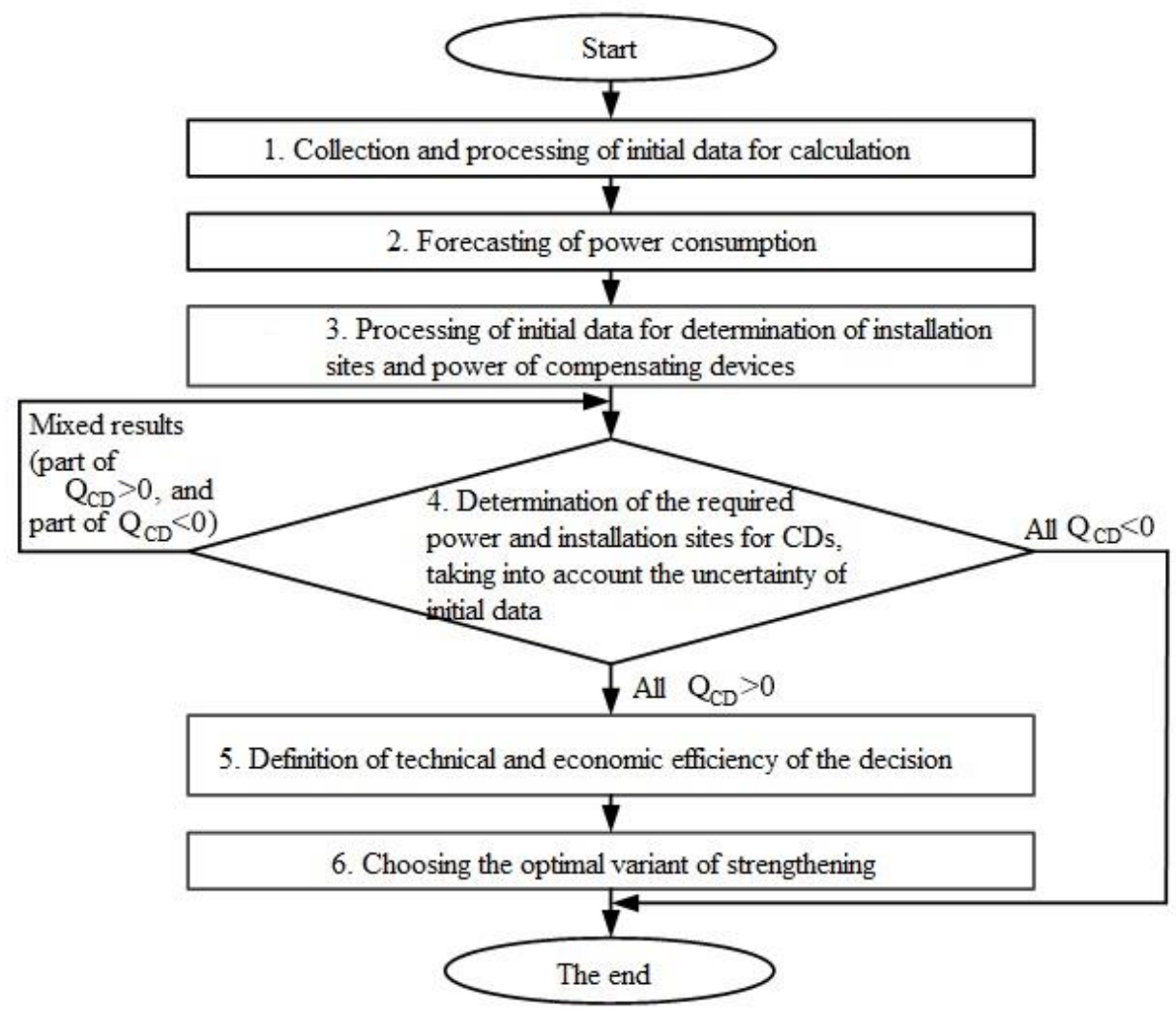

Fig. 2. Algorithm for choosing the optimal variant of strengthening the traction power supply system.

In the third block of the algorithm, data are processed to determine the installation sites and the power of compensating devices. Here, the transition from energy values to power values is carried out, while predicting by the method using correlation and regression analysis, the equivalent value of reactive power is determined. According to the schemes of external power supply of traction substations, computation graphs are compiled, and the distribution of capacities over their sections is calculated. In the subsequent calculation, the graphs are taken into account by the current distribution coefficients [15].

The fourth block of the algorithm consists in determining the installation sites and the power of compensating devices. To do this, an equation is used, which in the matrix form takes the form $[3,4]$ :

$$
\left[R_{\Sigma}\right] \cdot\left[Q_{C D}\right]=[X],
$$

where $\left[R_{\Sigma}\right]$ - matrix derived from active resistances and depending only on the topology of the network;

$\left[Q_{\mathrm{CD}}\right]-$ matrix of the unknown power of CD;

$[X]$ - matrix that combines the known coefficients $A_{n}$ and the known reactive power flows across the network elements, determined from the calculation of the mode before the installation of CD. The coefficients $A_{n}$ combine the technical and economic parameters of the designed $\mathrm{CD}$.

$$
A_{n}=\frac{\left[(\mathrm{E}+a) \cdot K_{0}+\Delta P_{s p} \cdot c_{0} \cdot T\right] \cdot U^{2}}{2 \cdot c_{0} \cdot T}
$$


where $K_{0}$ - cost of generating $1 \mathrm{kVAr}$ of reactive power;

$E$ - discount rate;

$a=a_{\mathrm{op}}+1 / T_{s}-$ additional coefficient;

$T_{\mathrm{sl}}$ - average service life of CD;

$a_{\mathrm{op}}-$ depreciation for operating costs;

$\Delta P_{\text {sp }}$ - specific losses in capacitors, $\mathrm{c}_{0}$ - cost of electric energy;

$T$ - operating time of $\mathrm{CD}, \mathrm{h} /$ year;

$U$ - voltage in the power supply system.

As a result of the execution of the fourth block, three types of results are possible. First, all the received power of compensating devices is positive. In this case, all design traction substations require the installation of compensating devices, and one should proceed to the fifth block of the algorithm. The second case is that all the received power is negative. This means that compensation is not required at the substations under consideration. And the third case is mixed results. In this case, it is necessary to repeat the calculation using formula (1), eliminating rows from matrices that correspond to negative results.

In the fifth block of the algorithm, technical and economic efficiency of using compensating devices is assessed. To assess the technical efficiency, it is proposed to use such indicators as unloading the power transmission lines and reducing the voltage losses up to the installation site of the compensating device.

By the size of unloading of power transmission lines, it is possible to judge the amount of reserve power that can be connected to this power transmission line. Besides, when the reactive power in the power transmission lines decreases, the current is proportionally reduced and, as a consequence, the voltage and power losses are reduced too.

The voltage level is an important parameter for the functioning of the railway, especially when handling freight trains of increased weight and high-speed trains. Without taking into account the distribution of voltage across the phases, the reduction in voltage losses for a particular traction substation can be determined by formula (3) as a percentage of the nominal voltage [15]:

$$
\delta U \cong \frac{Q_{c} \cdot X_{\Sigma}}{U_{r}^{2}}
$$

where $Q_{c}$ - power of CRP, kvar;

$X_{\Sigma}$ - reactive resistance of power transmission up to the installation site of CU, Ohm;

$U_{r}$ - rated voltage of the consumer (railway) network, $\mathrm{kV}$.

Assessment of economic efficiency is proposed to be implemented using such indicator as net discounted income. It includes a technical parameter for reducing power losses in transformers [15].

In the sixth block of the algorithm, the optimal variant of strengthening the traction power supply system is determined. The optimal variant is determined by the indicators of technical and economic efficiency, and also by the value of the calculated power of the compensating device. With its values below 1 MVAr, the installation is not recommended, but for large values, a distributed installation of compensating devices is recommended.

\section{Results}

According to the developed methodology, a calculation was made for the section of the Far Eastern Railway which includes nine traction substations. Calculations were made for two points: 2017 and 2020. In calculations for 2017, the actual values of power consumption were used. And in calculations for 2020, the forecasting of power consumption is applied using correlation and regression analysis. For forecasting electric power consumption, data on the 
planned increase in traffic volumes were used, taken from the conservative version of the "Strategy for the Development of Railway Transport in the Russian Federation until 2030".

An example of the computation graph for the Khabarovsk-II traction substation with the values of the power distributed over its sections before and after installation of compensating devices is shown in Figure 3. The results of calculations of installation sites and power of compensating devices are given in Table 1.
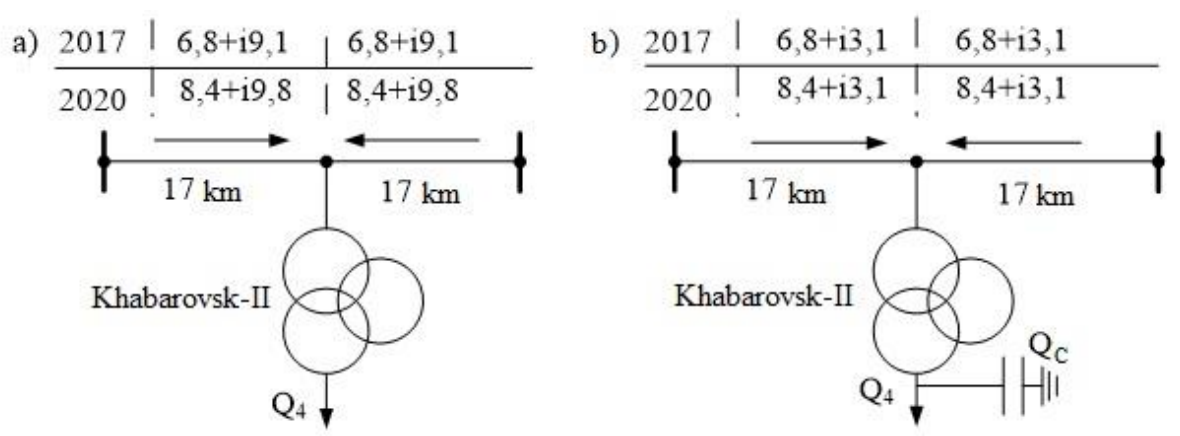

Fig. 3. Computation graph with the values of the powers distributed over its sections before (a) and after (b) the installation of compensating device.

Table 1. Results of calculations of installation sites and power of compensating devices.

\begin{tabular}{|l|c|c|}
\hline \multicolumn{1}{|c|}{ Substation } & $\begin{array}{c}\text { Power of compensating devices } \\
\text { on 2017, kVAr }\end{array}$ & $\begin{array}{c}\text { Power of compensating } \\
\text { devices on 2020, kVAr }\end{array}$ \\
\hline Ikura & Not required & Not required \\
\hline In & Not required & Not required \\
\hline Volochaevka & Not required & Not required \\
\hline Khabarovsk & 10874 & 13455 \\
\hline Krugliklovo & Not required & Not required \\
\hline Dormidontovka & 2194 & 6982 \\
\hline Avan & 1314 & Not required \\
\hline Rozengartovka & Not required & Not required \\
\hline Bikin & 1139 & \\
\hline
\end{tabular}

When installing devices of calculated power, the reactive power values will decrease at the sections of the external power supply system of the substations. The values of the total power before and after installation of compensating devices are shown in Figure 4. 


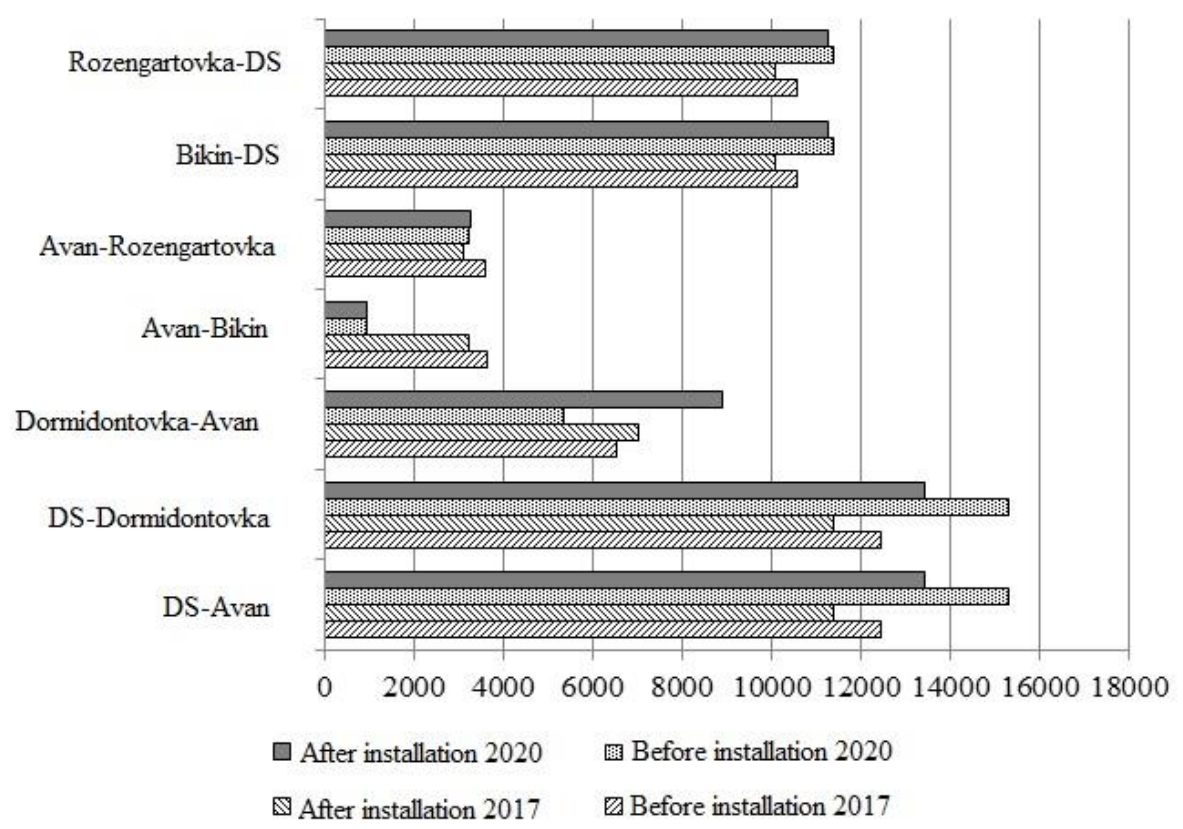

Fig. 4. Distribution of power on sections of power transmission lines before and after installation of compensation of reactive power for various options of calculations (DS - conventional designation of a distribution substation).

The greatest decrease in total power is observed at the sections of power transmission lines adjacent to the distribution substation, which indicates a decrease in the load of the latter. Based on the results of calculations, the following conclusions were formulated.

\section{Conclusions}

Increase of energy efficiency of distribution electric networks is possible with the use of reactive power compensating devices in the traction network. In this case, the load of power transmission lines is reduced to $70 \%$. By reducing the currents in power transmission lines and transformers, the bus voltage level $27.5 \mathrm{kV}$ is increased by up to $5 \%$ for 2017 and by up to $8 \%$ for 2020 . Net discounted income will be about 7.5 million rubles for 2017 and 6.9 for 2020 .

\section{References}

1. L.A. German, Adjustable installation of capacitive compensation in the traction power supply system of railways: Tutorial (FSBI:Educational and Methodological Center for Education in Railway Transport, Moscow, 2015)

2. L.A. German, Filter compensating installations in traction power systems of railways: monograph (Publishing House of National University of Economics, Knyagino)

3. Company Standard RZD 07.022.2-2015

4. Yu.V. Moskalev, G.G. Akhmedzyanov, Izvestiya Transsiba 2(26), 100-107 (2016)

5. Yu.V. Kondratiev, A.V. Tarasenko, Izvestiya Transsiba 2(22), 79-87 (2015) 
6. D.B. Aubakirov, Yu.V. Kondratiev, Innovation projects and technologies in education, industry and transport: proceedings of the scientific and practical conference dedicated to the Day of Russian Science (Omsk State Transport University, Omsk, 2014)

7. Le, Electrical Engineering 100(3), 1517-1533 (2017)

8. N.V. Raevsky, V.G. Litvintsev, Modern technologies. System analysis. Modeling 4, 192-196 (2010)

9. E. Sigel, Practical business statistics, Ed. 4th. (Williams Publishing House, Moscow, 2012)

10. N. Draper, G. Smitt, Applied regression analysis: Book 2 (Finances and Statistics, Moscow, 1987)

11. S. Haykin, N.N. Kussul, A.Yu. Shelestova, Neural networks: Full course (Williams Publishing House, Moscow, 2006)

12. S.D. Shtovba, Designing of fuzzy systems by means of MATLAB (Hot line - Telecom, Moscow, 2007)

13. N.V. Savina, Yu.V. Myasoedov, A.A. Kazakul, The Bulletin of the Irkutsk State Technical University 6(53), 130-137 (2011)

14. N.V. Savina, A.A. Kazakul, Method of optimal compensation of reactive power in grid distribution companies in conditions of uncertainty, The Bulletin of the Ivanovo State University, 42

15. V.N. Li, N.K. Shurova, Izvestiya Transsiba 3(27), 38 - 44 (2016) 